\title{
MEMÓRIAS SOBRE O IMPERADOR VALENTE NOS TESTEMUNHOS DOS PADRES CAPADÓcIOS: a morte do imperador e denúncias contra o cristianismo ariano (séc. IV d.C.) \\ Helena Amália PAPA \\ (D) helena.papa@unimontes.br \\ Universidade Estadual de Montes Claros, Montes Claros, Minas Gerais, Brasil
}

Memories about Emperor Valens in the Testimonies

of the Cappadocian Fathers: the Death of the Emperor

and Denouncements against Arianism (4th Century AD)

\section{RESUMO}

Os Padres Capadócios, bispos Basilio de Cesareia, Gregório de Nazianzo e Gregório de Nissa, ficaram assim conhecidos pela historiografia e pela literatura patrística por terem nascido, vivido e morrido na Província da Capadócia, no Oriente do Império Romano, atual Turquia, durante a segunda metade do século IV d.C. Entretanto, os três cristãos nicenos não tiveram suas vidas coadunadas na historiografia unicamente por serem conterrâneos: os três participaram dos mesmos conflitos político-religiosos, envolvendo a defesa do dogma trinitário. A relação entre o poder imperial e os grupos cristãos, e as relações entre os próprios Cristianismos, foi um dos temas protagonistas no século IV d.C. A partir de uma análise crítica dos testemunhos dos Padres Capadócios sobre o imperador Valente (364378 d.C.), pretendemos enfatizar a relação entre os cristãos arianos e nicenos, uma vez que, em seus testemunhos, esses bispos auxiliaram na construção da imagem de Valente como inimigo estritamente religioso dos nicenos. Tal imagem foi utilizada pela historiografia para construção de uma memória que insere a morte desse imperador como um marco historiográfico acrítico que separa a perseguição de uma liberdade religiosa para os nicenos, que findaria em uma oficialização do Cristianismo niceno por Teodósio I em 380 d.C.

Palavras-chave: Relações de Poder, Antiguidade Tardia, Padres Capadócios, Morte, Imperador Valente.

\begin{abstract}
The Cappadocian Fathers, Bishops Basil of Caesarea, Gregory of Nazianzus and Gregory of Nyssa, were known for historiography and patristic literature for being born, living and dying in the Province of Cappadocia, in the east of the Roman Empire, present-day Turkey, during the second half of the 4th century AD. However, the three Nicene bishops did not have their lives connected to historiography just because they were compatriots: they participated in the same politicoreligious conflicts, which involved the defense of the Trinity doctrine. The relationship between imperial power and Christian groups, as well as the relationship between Christianity-followers themselves, was one of the leading themes in the 4th century AD. Based on a critical analysis of the Cappadocian Fathers' testimonies about Emperor Valens (364-378 AD), we intend to emphasize the relationship between Arian Christians and Nicene Christians, since, in their testimonies, these bishops assisted in the construction of Valens' image as a strictly religious enemy of the Nicenes. Such an image was used by historiography to construct a memory that inserts the death of this emperor as an uncritical historiographic landmark that separates persecution and religious liberty for the Nicenes, which would be ended by Theodosius I officialization of the Nicene Christianity in 380 AD.
\end{abstract}

Keywords: Power relationship, Late Antiquity, Cappadocian Fathers, Death, Emperor Valens. 


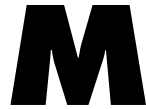

arcos historiográficos sempre foram e continuam sendo (re)criados pelos historiadores. Entretanto, por própria definição, a História está em constante mudança, uma vez que cada contexto, local e temporalidades distintas suscitam novos olhares e direcionamentos para o objeto. O nosso "fazer história" deve, portanto, estar atento a essas cristalizações historiográficas e disposto a repensar determinados eventos. A História do Cristianismo, como tantas outras, não ficou isenta dessas cristalizações, pois esteve, durante muito tempo, atrelada à literatura patrística, cujo olhar para o passado foi direcionado para o triunfo dos cristãos, mais especificamente, o triunfo de um determinado grupo, os cristãos nicenos, em detrimento dos outros Cristianismos. É o que nos recorda Ramon Teja em sua obra Organizacion Economica y Social de Capadocia en el siglo IV, segun los Padres Capadocios (1974), acerca dos três principais obstáculos que necessitamos enfrentar ao estudar as obras dos Padres Capadócios:

\begin{abstract}
O aproveitamento da patrística como fonte histórica oferece uma série de dificuldades bem conhecidas por todos. Por um lado, está a falta de edições críticas e estudos de fontes que afetam quase todos os autores. De outro, está a insegurança na atribuição de numerosas obras aos autores. Outro obstáculo resulta do próprio caráter de quase toda a totalidade da produção patrística. A maior parte desta, constitui-se de tratados teológicos, sermões morais, cartas, etc., obras que, por um lado foram escritas para um fim muito distante daquele que leva a leitura do historiador, por outro, estão totalmente impregnados do estilo retórico dominante da época que levam a sérias dificuldades de interpretação (TEJA, 1974, p. 10. Grifos nossos).
\end{abstract}

A morte do imperador Valente foi e ainda é analisada como um divisor entre um período de perseguição e um período de liberdade aos cristãos nicenos. Nessa ótica, após a morte de Valente, a narrativa sobre esse grupo foi triunfante, posta em marcha para sua oficialização em 380 d.C. pelo imperador Teodósio I. Acreditamos que tal cristalização historiográfica contribuiu para que as explicações puramente religiosas sobre esse período fossem proeminentes e satisfatórias durante muito tempo.

Valente se tornou imperador em 364 d.C. para governar com seu irmão, Valentiniano I, proclamado imperador no mesmo ano por uma reunião que agrupou altos cargos oficiais militares e civis, acontecimento comum desde meados do século III d.C. e, principalmente, ao longo do século IV d.C., uma vez que a sucessão imperial romana estava cada vez mais relacionada com o Exército Romano, como nos lembra Bruna Campos Gonçalves (2015). Assim sendo, aqueles irmãos que seriam futuros imperadores, já atuavam no exército como oficiais da cavalaria, posição proporcionada pela função de general que seu pai exercia (Temístio, Disc. VI, Sobre o amor fraterno).

\title{
Memórias sobre o imperador Valente
}

As memórias sobre Valente, imperador que governou a porção oriental do Império Romano, durante os anos de 364 a 378 d.C., esteve, durante muito tempo, estruturada 
sobre dois alicerces fundamentais que envolvem sua morte, em 378 d.C. O primeiro, cujo aspecto norteador seria sua incapacidade bélica, foi demarcado pela derrota na Batalha de Adrianópolis, contra os godos, batalha da qual saiu morto. Já o segundo alicerce, que também contribuiu para uma visão derrotista e negativa de Valente, esteve atrelado às questões político-religiosas de seu governo, uma vez que a morte do governante teria liberado o Império da perseguição que ele perpetrou àqueles contrários aos grupos religiosos que professavam o arianismo, principalmente, o arianismo homeu'1.

Esses alicerces, norteados pela morte de Valente, estruturaram uma memória historiográfica relacionada a uma incapacidade bélica e falta de diplomacia, desse governante, ao lidar com os grupos religiosos que, juntamente com outras representações consideradas depreciativas, determinaram o ônus de mau imperador que, por ter sido derrotado, teria perdido a integridade territorial do Império, culminando, em torno de 100 anos depois, no final do Império Romano.

No que pese as questões sobre as práticas bélicas de Valente, é nosso objetivo nesse artigo problematizar o segundo alicerce mencionado, ou seja, aquele que permeia as questões político-religiosas que envolvem o imperador Valente e os Padres Capadócios. A partir de uma análise crítica dos testemunhos dos Padres Capadócios sobre o imperador Valente (364-378 d.C.), pretendemos enfatizar a relação entre os cristãos arianos e cristãos nicenos, uma vez que, em seus testemunhos, esses bispos auxiliaram na construção de uma imagem de Valente como inimigo estritamente religioso dos nicenos. Tal imagem foi utilizada pela historiografia para construção de uma memória que insere a morte desse imperador como um marco historiográfico acrítico que separa, de forma estanque: a perseguição de uma liberdade religiosa para os nicenos, que findaria em uma suposta oficialização do Cristianismo niceno por Teodósio I em 380 d.C. Não é nossa intenção relativizar aqui a perseguição aos nicenos e/ou o apoio aos arianos homeus proporcionado e patrocinado pelo imperador Valente, mas sim partir de uma indagação que essa História está sendo feita e refeita, contada e recontada por nós, historiadoras e historiadores, partindo sempre da premissa da oficialização por Teodósio em 380 d.C. A partir do marco historiográfico da oficialização, os eventos anteriores teriam que entrar em uma narrativa que levasse àquela conclusão.

Na primeira década de nosso século, notamos uma historiografia preocupada em revisitar representações imperiais que produziram e/ou reproduziram alicerces como esses, sem a criticidade necessária diante da documentação e da historiografia, colaborando assim para uma nova compreensão sobre os imperadores.

No tocante a personagens específicas do recorte cronológico, espacial e temático desse artigo, como nos lembra Érica Cristhyane Morais da Silva (2012, p. 142), a memória historiográfica dos imperadores Juliano e Constâncio II receberam novos olhares proporcionando novas compreensões historiográficas sobre esses governos e governantes. Estudos nacionais encabeçados no início dos anos 2000, (SILVA, 2003; CARVALHO, 2010) mostram essa revisitação, aos quais, acrescentamos os estudos da já citada Érica Morais da Silva (2012), que abarcam o imperador Teodósio I. 
Nessa mesma perspectiva é que o historiador Noel Lenski, em livro publicado em 2002, Failure of Empire: Valens and the Roman State in the Fourth Century Ad, também pretendeu revisitar a memória do imperador Valente. Considerada, ainda hoje, como uma das obras mais importantes e abrangentes sobre Valente, objetiva devolver à memória sobre o imperador uma abordagem coadunada ao contexto que vivenciou, nas palavras de seu autor: um contexto notavelmente complexo.

Lenski não pretendeu eximir Valente de nenhum ônus, mas se propôs a esclarecer pontos nos quais acredita que as fontes foram longe demais por depreciá-lo. Ao citar Amiano Marcelino, pelo qual nos conta que "o imperador Valente era um homem com igual quantidade de qualidades extraordinárias e terríveis”, Lenski afirma que Valente "não era nem um herói, nem um monstro, mas sim um humano ordinário diante uma tarefa extraordinária. Este livro é sobre o homem e a tarefa, sobre Valente e seu Império" (LENSKI, 2002, p. 1).

Apesar de considerada uma obra que preenche uma real necessidade historiográfica sobre Valente, este estudo recebeu críticas concernentes ao olhar despendido à Amiano Marcelino por Lenski. Esse é o posicionamento do historiador David Woods (2004), em resenha sobre o livro, publicada no Journal of Roman Archaeology. Woods discorda da leitura e compreensão que Lenski direcionou à obra de Amiano Marcelino.

Amiano Marcelino, em sua Res Gestae, dedica parte do livro XXX para exaltar virtudes e depreciar o que considera como defeitos de Valentiniano I. Após elogiar vários elementos bélicos do governante, Amiano exalta a neutralidade de Valentiano em assuntos religiosos. Concordamos que tal questão deve ser vista com muita cautela quando comparada às ações de Valente. A comparação desse comportamento de Valentiniano I, descrito por Amiano, com o comportamento de Valente levou os pesquisadores a inferências historiográficas bastante problemáticas, tal como como aquela interpretação feita em estudos anteriores, exposta aqui com o intuito de ser retificada, mas que ainda são constantemente reproduzidas pela historiografia:

\footnotetext{
Durante essa diarquia, o imperador Valentiniano I, responsável pela administração imperial na parte ocidental do Império Romano, era cristão niceno, assim como Constante o havia sido. Tudo indica que Valentiniano I estava mais preocupado em reunir forças do exército nas fronteiras do que participar das discussões teológicas do período. É claro que não acreditamos na inexistência de conflitos político-religiosos no Ocidente, porém tais contendas devem ter sido mais amenas em comparação ao restante do território romano (PAPA, 2013, p. 80-81).
}

Com o intuito de revisitar a imagem de Valente é que utilizamos os testemunhos dos Padres Capadócios a fim de demonstrar que a morte do imperador interpretada como marco historiográfico que representou a liberdade para os cristãos nicenos foi resultado de uma análise acrítica e não intertextual desses documentos históricos. Sendo assim, ao trabalharmos com esses três autores, bispos cristãos nicenos, almejamos, por meio da intertextualidade de seus relatos, compreender como 
foram criadas as memórias sobre o Imperador Valente a partir de denúncias contra o Cristianismo ariano.

\section{Os testemunhos dos Padres Capadócios}

A relação entre o poder imperial e os grupos cristãos, e as relações entre os próprios Cristianismos, foi um dos temas protagonistas no século IV d.C. Esse estudo prioriza conflitos político-religiosos que ocorreram na porção oriental do Império Romano, na segunda metade do século IV d.C., entre duas correntes do Cristianismo, inseridas dentre uma variedade de grupos que coexistiram naquele cenário, a saber: os cristãos nicenos e os cristãos arianos, mais especificamente, o recorte está direcionado para o Cristianismo ariano homeiano. Os cristãos nicenos ficaram assim conhecidos, pois estavam atrelados às decisões do Concílio de Niceia, ocorrido em 325 d.C., do qual seu grupo saiu vencedor, cuja interpretação doutrinária compreendia que a trindade era composta de três pessoas e uma única substância, que era divina, indivisível e consubstancial aos três estados. Para o segundo grupo, os cristãos arianos homoianos, a substância divina deveria ser hierarquicamente proporcional às pessoas e, portanto, obedeceria em maior estado à primeira pessoa do dogma trinitário, ao Pai, e consequentemente ao Filho e, ainda em menor estado, ao Espírito Santo.

A atitude adotada pelo imperador Constantino ao decretar que o grupo dos cristãos nicenos, que apoiavam a consubstancialidade do dogma trinitário, era o correto (ortodoxo), foi a de condenar os sacerdotes discordantes à infâmia. Segundo Caroline Humfress (2007, p. 225), tal sentença já fazia parte das leis romanas. Ainda segundo a historiadora britânica, a infâmia envolvia a pessoa a uma diminuição em termos legais, com implicações que envolviam julgamentos civis e criminais, desqualificando-a para cargos públicos.

Os Padres Capadócios, bispos Basílio de Cesareia (329/331-378 d.C.), Gregório de Nazianzo (325-390 d.C.) e Gregório de Nissa (335/340-394 d.C.), ficaram assim conhecidos pela historiografia e pela literatura patrística por terem nascido, vivido e morrido na Província da Capadócia, atual Turquia, durante a segunda metade do século IV d.C. Entretanto, os três cristãos nicenos não tiveram suas vidas coadunadas na historiografia unicamente por serem conterrâneos: os três participaram dos mesmos conflitos político-religiosos, envolvendo a defesa do dogma trinitário.

Após a experiência durante o governo do imperador Constantino e de sua postura intervencionista nos assuntos do Cristianismo, via patrocínio imperial, segundo Averil Cameron (1991, p. 22), foram os próprios bispos que solicitaram a intervenção do poder central e tentavam influenciar as decisões do imperador, disputando, inclusive, lugares proeminentes na hierarquia citadina, como pode ser observado:

Constâncio II e Valente, por exemplo, patrocinadores de uma forma de arianismo moderado, tentaram de todos os modos, inclusive com força, impor suas convicções, perseguindo não só os que eram contrários ao arianismo, mas também os que, no seio deste, não estavam dispostos a aceitar a mesma fórmula de 
fé que o imperador queria. Daí ameaças, deposições, exílios em sés longínquas, [...], para que não empreendessem uma eficaz oposição (MORESCHINI; NORELLI, 2000, p. 49).

Defendemos uma via interpretativa que compreende que os bispos buscavam legitimidade junto ao poder imperial, porque não havia, no período em questão, uma autoridade eclesiástica capaz de corroborar as decisões de determinado concilio. O que estamos queremos dizer é que não havia, nesse momento, uma hierarquia legítima de determinados bispos sobre outros, para que um deles pudesse determinar o que seria aceito como verdade e qual posicionamento tomar diante de determinadas querelas.

A hierarquia, nesse momento, ocorria por meio do prestígio concedido pela aproximação com o poder imperial e de sua esfera administrativa. Essa aproximação poderia ocorrer geograficamente ou, até mesmo, por meio de ideais político-religiosos em comum. Dessa forma, quando o imperador Valente exilava bispos e torturava monges nicenos, outros grupos religiosos mostravam-se dotados de apoio imperial, que poderia representar certa legitimidade - seja ela obtida por meio da força ou não.

Durante o governo de Valente ocorreram vários embates entre bispos cristãos nicenos e funcionários imperiais arianos como deposições de bispos nicenos, tortura, exílios e divisão territorial de suas dioceses. Este artigo tratará especificamente dos testemunhos sobre Valente que, em nossa opinião, auxiliaram na compreensão e na construção da memória que envolve a sua morte, como um separador de um período que antes perseguia os cristãos nicenos, do período em que os nicenos teriam sido agraciados com apoio imperial, em detrimentos dos outros Cristianismos. Para exemplificar a questão, selecionamos testemunhos sobre Valente sobre as temáticas: deposições, exílios e tortura. ${ }^{2}$

\section{Denúncias contra o Cristianismo ariano: deposições, exílios e tortura}

As informações contidas nas cartas escritas sob e/ou sobre o governo de Valente contém muitas informações no tocante à deposição de bispos, torturas, exílio e, muitas vezes, consequentemente, as interferências administrativas.

Algumas missivas retratam de forma direta a violência presente no conflito políticoreligioso-administrativo. As cartas 139 (373 d.C.), 256 (376 d.C.) e 257 (376 d.C.), de Basílio de Cesareia, denunciam a perseguição e maltrato aos monges pelos arianos durante o governo de Valente.

Na carta 139, enviada aos habitantes da cidade de Alexandria, para consolá-los de um ataque do poder imperial, podemos notar o relato da prática da tortura:

[...] nossos ouvidos são tocados, por isso, nós temos que aprender a imprudência e a odiosa heresia de nossos perseguidores. Escutamos que eles não tiveram respeito nem pelos idosos, nem pelos trabalhadores da vida monástica, nem amor aos povos; que eles chegaram até a torturar os corpos, desonrando-os e entregando-os ao exílio; que eles pilharam os bens daqueles que não puderam encontrar; sem 
recear a condenação dos homens, sem prever o terrível castigo do justo Juiz! (BASÍLIO DE CESAREIA, Carta 139, escrita em 373 d.C. Enviada aos habitantes de Alexandria).

Os receios de Basílio de Cesareia e Gregório de Nazianzo são perceptíveis uma vez que a, considerada por eles, guerra herética possibilitou o exílio de vários bispos nicenos (temática presente em mais de 30 missivas do epistolário de Basílio, cartas 21, 68, 139, 181, 182, 183, 195, 168, 195, 215, 217, 225, 237, 242, 243, 247, 248, 254, 256, $257,264,265,266,267,268,270,287)$. Esses exílios eram exercidos pelos prefeitos do pretório e decretados pelo próprio imperador.

Segundo Miguel Spinelli (2002, p. 244), durante o período do governo de Valente, além do número de bispos arianos ter aumentado consideravelmente, eles passaram, também, a ocupar cargos proeminentes nas principais cidades do Império Romano Oriental.

O exílio proporcionava a troca de autoridades eclesiásticas em determinadas sedes episcopais, assim, Basílio e Gregório Nazianzeno mostram-nos suas preocupações com o exílio, e sua consequência, a chegada de bispos arianos: "[...] essa situação é ainda incerta, pois, se Évippios chegar, ele e seus discípulos nos ameaçarão, também, de uma certa aglomeração de pessoas que partilham de seus sentimentos" (BASÍLIO DE CESAREIA, Carta 68, escrita em 371 d.C. Enviada à Melécio, bispo de Antioquia).

Em várias cartas $(168,181,182,183,225,267)$, Basílio presta condolências e denuncia o fato de alguns bispos, seus amigos, estarem exilados. Podemos extrair vários excertos que demonstram a dispersão que os nicenos sofreram devido ao exílio durante o governo de Valente. As passagens abaixo equiparam o afastamento geográfico forçoso, ou seja, a dispersão de bispos exilados em regiões afastadas, à uma punição injusta e caluniosa, sem provas.

[...] Eu escrevo à tua piedade e te agradeço por transmitir o conteúdo desta carta. Assim eu te aconselho a rezar por nós, a fim de que o Senhor diminua nossas aflições e que Ele afaste de nós, como uma nuvem, o peso da dor que está em nosso coração. O que ocorrerá com o retorno dos bispos muito amados por Deus que se encontram atualmente dispersos e que foram punidos por sua justa devoção (BASíLIO DE CESAREIA, Carta 195, escrita em 375 d.C. Enviada a Euphorions, bispo da colônia da Armênia).

Se as terríveis ameaças do Senhor não têm nos instruído, se tais golpes não nos fazem sentir que é por causa da nossa inquietude que o Senhor nos abandonou e que por isso os bispos foram conduzidos à dispersão (BASÍLIO DE CESAREIA, Carta 21, 84 escrita em 375 d.C. Enviada a um bispo).

Alguns malfeitores não são condenados sem provas, mas os bispos são condenados por uma única calúnia e, mesmo sem a menor prova em favor dos acusadores, eles são entregues aos seus suplícios. Mesmo que eles não conheçam as acusações não possuem direito a um tribunal, que são vítimas de calúnias 
e são conduzidos a força a uma hora oportuna da noite, são exilados para regiões longínquas (BASÍLIO DE CESAREIA, Carta 242, 2, escrita em 376 d.C. Enviada aos bispos ocidentais).

Os períodos de afastamentos forçados de determinadas personagens na Antiguidade são temas recorrentes na documentação sobre esses períodos. Em primeira instância, objetiva-se com o afastamento, o distanciamento e separação do considerado errante do conflito em questão, constituindo-se como uma manifestação de intolerância e um instrumento de repressão contra o oponente. Entretanto, na opinião da historiadora espanhola María Victoria Escribano Paño (2003, p. 183) os afastamentos geográficos na antiguidade resultaram em uma grande circulação de ideias e pessoas e, consequentemente, auxiliaram na propagação do que inicialmente se aspirava extirpar e isolar.

No decorrer de sua atuação episcopal, Gregório de Nissa foi exilado em dois momentos distintos. Durante esses dois episódios, Gregório sofreu afastamentos forçosos de sua cidade, Nissa e de suas atuações episcopais. Esses dois períodos de reveses são primordiais para compreendermos as práticas políticas e culturais que envolveram o exílio, bem como o retorno desse banimento de Gregório, pois o bispo niceno teria que angariar apoio e suporte dos seus pares para retornar ao seu bispado, visto que, no período em questão havia uma disputa de forças entre os adeptos dos vários tipos de Cristianismos.

Sendo assim, mais especificamente na controvérsia ariana, discussão em Gregório participou, além da base teológica do dogma trinitário, o que também estava em discussão nos sínodos e concílios era o cargo mais proeminente na hierarquia eclesiástica nesse momento: o episcopos. Assim, por meio de deposições e exílios, as autoridades eclesiásticas disputavam as sedes episcopais e os bispados em cidades importantes na teia administrativa do Império.

Dessa forma, a relação entre o político, o religioso e o jurídico se faz presente, uma vez que o exílio pode ser equiparado, nesse momento, a instrumentalização de uma marginalização geográfica como método para tentar resolver as rivalidades religiosas, logo, esse "afastamento forçoso conflui tanto uma tradição jurídica penal como os procedimentos de um inimigo político" (ESCRIBANO PAÑO, 2003, p. 207).

A questão do retorno do exílio traz informações importantes para essa reflexão, uma vez que muitos bispos e monges exilados puderam retornar aos seus espaços de atuação após a morte do imperador Valente. Ao analisar os casos de bispos que retornaram do exílio, Peter Van Nuffelen (2008, p. 147) utilizou-se, consequentemente, de casos de exílio do tipo relegação e banimento 3 para mostrar "a importância de uma dimensão política vista pela ótica de uma decisão jurídica". Nessa visão, com a anistia ou indulgência de algum imperador, seja pela morte de seu antecessor, ou por uma postura político-religiosa diferente, o retorno desses bispos traria uma conotação política à dimensão jurídica, que nós estendemos à religiosa: ao retornar, o exilado reclamaria sua posição anterior ao poder civil, nas tarefas que já exercia, 
bem como aos seus pares, contribuindo ainda mais para a efervescência políticoreligiosa desses conflitos.

Assim, entendemos que a morte de um imperador, como a de Valente, sucedida pelo governo de um imperador de postura politico-religiosa diversa, favorável a outro grupo religioso, não bastaria para proporcionar a tão almejada liberdade religiosa promulgada pela historiografia. A morte de Valente proporcionou o retorno de vários bispos do exílio, tais bispos buscaram o lugar que tinham antes, acirrando, ainda mais, as disputas de poder.

\section{Exílios de Gregório de Nissa e Basílio de Cesareia}

O exílio do bispo Gregório perpetrado pelo imperador Valente nos foi legado por meio dos testemunhos dos três capadócios. O próprio Nisseno nos relata esse episódio por meio de seus discursos Vida de Santa Macrina (Seções 15, 21) e Contra Eunômio, livro 1, bem como por meio de seu epistolário (Cartas 5, 6, 18, 19, 22). Seu irmão Basílio e o contemporâneo Gregório de Nazianzo também abordaram a temática em suas missivas (epístolas 225, 231, 232, 239 e epístolas 72, 73, 74, 76, respectivamente).

Esses relatos nos proporcionam informações dos momentos de confinamento que Gregório de Nissa teria passado. Os motivos que levaram ao exílio-banimento do Nisseno ainda são bastante incertos na historiografia. Os excertos, como exemplificado abaixo, apontam que tal ato foi cometido por Valente pelo fato deste imperador ter uma fé diferente da sua, obrigando Gregório a lutar a favor da sua fé.

Da minha parte, eu disse a ela [Macrina] as dificuldades em que eu me encontrava quando o imperador Valente me exilou por causa da sua fé, quando a confusão nas igrejas me convocou para as controvérsias e lutas (GREGORIO DE NISSA, VSM, 21, 1-5).

A mesma argumentação pode ser notada no testemunho de Basílio de Cesareia sobre o exílio-banimento do irmão. O Cesareno escreve para sua rede de sociabilidade para angariar apoio à causa do irmão:

Rezem para que Deus conceda a ele [Gregório de Nissa, que se encontrava exilado], enfim, ver a devoção curada das feridas causadas pelas fraquezas heréticas [...] (BASILIO DE CESAREIA, Carta 232 datada em 375-376 d.C., enviada ao bispo Anfilóquio de Icônio).

Os testemunhos que contém mais informações sobre esse exílio-banimento são as cartas 6 e 18 do próprio Gregório. Sua missiva 6 foi endereçada ao bispo Ablábio para agradecer por sua hospitalidade durante a viagem de retorno à cidade de Nissa, após o período que permaneceu exilado. A partir disso, a datação dessa carta é de 378 d.C., o que coincide com a morte do imperador Valente. 
Em vários momentos dessa carta, cuja temática percorre a viagem de volta à cidade de Nissa, após o exílio, podemos detectar a preocupação de Gregório em mostrar que era venerado pela população das cidades em que passava (Carta 6, 6,9), principalmente pela população de sua própria cidade Nissa (Carta 6,11).

Toda a nossa jornada esteve cheia de pessoas por causa das várias habitações que existiam. Algumas vieram ao nosso encontro, outras nos acompanharam trazendo incentivo e lágrimas de alegria (GREGÓRIO DE NISSA, Carta 6,6 datada em 378 d.C.).

Temos conhecimento que esse exílio-banimento foi posterior a um julgamento, no qual Gregório de Nissa foi declarado culpado. Tratou-se de um sínodo ocorrido em 375 d.C., no qual a maioria dos partícipes eram adeptos ao arianismo cujo representante do imperador foi o Vicário da Diocese do Ponto, Demóstenes, conforme apontado por Basílio nos fragmentos citados. Pelas denúncias, podemos inferir que Basílio critica a própria hierarquia formada para punir o irmão:

O tribunal nos desprezou e seu poder, emudecido pelos insultos de Filocares, ordenou acusar e exilar nosso irmão e colega Gregório (BASÍLIO DE CESAREIA, Carta 225 datada em 375 d.C., enviada ao funcionário imperial Demóstenes).

Um vicário [Demóstenes] chegou: foi o primeiro e o maior dos infelizes. Se esse homem tem sentimentos heréticos, eu não sei; em todo o caso ele é amigo dos heréticos e ele aprova com afeição que eles nos odeiem [...] (BASILIO DE CESAREIA, Carta 237,2 datada em 376 d.C., enviada ao bispo Eusébio de Samosata).

A missiva 225 do Cesareno nos fornece informações acerca das razões do julgamento dirigido ao Nisseno. Segundo esse testemunho, Gregório teria sofrido acusações que envolviam um desfalque econômico e fraude nos assuntos financeiros de seu bispado, provavelmente relacionado a alguma obra arquitetônica que Gregório estaria realizando na cidade de Nissa e uma acusação de ordem canônica relativa à sua ordenação episcopal, motivo esse que não será problematizado neste artigo.

Basílio foi outro capadócio que também obteve seu exílio perpetrado pelo imperador Valente. Entretanto, por motivos bastante contraditórios e escassos, o fato desse exílio não ter se efetivado ainda é desconhecido.

Basílio, bispo da capital da Província do Capadócia, Cesareia, enviou várias cartas para Modesto, prefeito do pretório da importante cidade no Oriente. As temáticas são variadas: solicitação de isenção de impostos aos ministros religiosos (carta 104, 372 d.C.), diminuição de altos impostos â população (Carta 110, 372 d.C.), clemência junto ao imperador para não divisão da Província da Capadócia (Cartas 279, 280 e 281). Em torno de 377 d.C. temos notícias, por meio do epistolário do próprio Basílio 
e de Gregório de Nazianzo, de uma contenda entre Basílio de Cesareia e o citado Prefeito do pretório Modesto.

Diante de tal conflito, o ocorrido com o prefeito pretoriano ocasionou a elaboração de um decreto em 377 d.C. no qual o imperador Valente determinava o exílio de Basílio. Entretanto, o bispo não foi exilado, talvez Valente tenha recuado em sua decisão por motivos político-religiosos ainda não decifrados pela historiografia consultada, talvez ele, ou próprio Basílio teriam morrido antes do exílio ser efetivado, uma vez que o bispo faleceu em 378-379 d.C., data próxima do falecimento do imperador. ${ }^{4}$

\section{Considerações finais}

Podemos notar que, mesmo após 378, com a morte de Valente, e mesmo após 380 d.C., com a demarcação historiográfica da oficialização do Cristianismo, ser niceno era um assunto complexo e de difícil definição. Na prática, é de nosso conhecimento que o arianismo e outros tipos de Cristianismos sobreviveram no Império Romano, principalmente no Ocidente até meados do século VII d.C.

A interpretação acrítica dessas temáticas (tortura e exílio), testemunhadas pelos Padres Capadócios, colaboraram para que a historiografia identificasse a morte de Valente como o marco para um caminho que culminaria na liberdade dos cristãos nicenos. É fato que, após a sua morte, muitos bispos puderam retornar do exílio. Este foi o caso de Gregório de Nissa, que só pôde retornar à sua sede episcopal após a indulgência de Graciano em 378 d.C., imperador com uma postura político-religiosa a favor dos nicenos, ocasião em que vários eclesiásticos nicenos retornaram (ou tentaram) aos seus postos, mas isso não o impediu de ser novamente preso em 380 d.C., já sob o governo de Teodósio I, por seus próprios pares.

Compreendemos que a historiografia influenciada pela literatura patrística conferiu à constitutio XVI,1,2 do Código Teodosiano a memória do discurso vencedor: a compreensão do dogma trinitário amplamente aceita pelo Ocidente católico foi aquela defendida e "oficializada pelo imperador cristão Teodósio I".

Nesse sentido, os acontecimentos anteriores a 380, como a morte de Valente, ficaram historiograficamente fadados à interpretação que culmina na oficialização. Tal visão continua sendo reproduzida na historiografia, corroborando para uma memória historiográfica sobre a morte de Valente como marco que separa momentos de reveses dos momentos vitoriosos para nicenos.

Nessa perspectiva, a morte do imperador se torna em um marco historiográfico que separa a perseguição da liberdade proporcionada aos cristãos nicenos, aquela corrente que seria declarada como oficial, por essa mesma historiografia, três anos depois, em 380 d.C.

A respeito de Valente ainda prevalece a História contada pelos vencedores: ele, cristão ariano, teria perseguido, torturado, violentado, exilado aqueles que foram determinados, posteriormente, os verdadeiros cristãos, os nicenos. Após a sua morte, esse grupo teria adquirido um êxito crescente, narrativa essa recriada por uma literatura 
patrística que culmina (ou se inicia) em outro marco historiográfico criado por essa narrativa: o da oficialização do Cristianismo.

Por fim, este artigo pretendeu revisitar esse marco historiográfico que, até então, não é temática das novas propostas de revisitação das imagens dos imperadores, ainda em curso, desde o início do século XXI. Enquanto isso, a morte do imperador Valente ainda é vista como um marco libertador para os "verdadeiros cristãos", cabendo a nós, tardo-antiquistas, continuarmos revisitando a temática a fim de colaborar com a questão.

\section{Referências}

CAMERON, Averil. The Later Roman Empire. Cambridge: Harvard University Press, 1993.

CARVALHO, Margarida Maria de. Paideia e Retórica no Século IV d.C.: A Construção da Imagem do Imperador Juliano Segundo Gregório Nazianzeno. São Paulo: Annablume/ FAPESP, 2010.

DELMAIRE, R. Exil, relégatio, déportation dans la législation du Bas-Empire. In: BLAUDEAU, P. (org.). Exil et relégation les tribulations du sage, et du Saint durant l'Antiquité Romaine et Chrétienne (ler-Vle s.ap.J.-C.). Paris: De Boccard, 2008, p. 115-132.

ESCRIBANO PAÑO, María Victoria. Intolerancia Religiosa y Marginación Geográfica en el S. IV d.C.: Los Exílios de Eunomio de Cízico. Stud, hist, Hg antig., Salamanca, n. 21, p. 177-207, 2003.

GONÇALVES, Bruna Campos. Comparações dos conceitos de realeza de Temístio e Amiano Marcelino: os casos de Joviano e Valentiniano (363-375 d.C.). São Paulo: Annablume/FAPESP, 2015.

HUMFRESS, Caroline. Orthodoxy and the Courts in Late Antiquity. Oxford: Oxford University Press, 2007.

LENSKI, Noel. Failure of Empire: Valens and the Roman State in the Fourth Century Ad. Berkeley: University of California Press, 2002.

MORESCHINI, Cláudio; NORELLI, Enrico (org.). História da Literatura Cristã Antiga Grega e Latina. São Paulo: Loyola, 2000.

PAPA, Helena Amália. A Contenda entre Basilio de Cesareia e Eunômio de Cízico (Séc.: IV d.C.): uma análise político-religiosa. São Paulo: Annablume/FAPESP, 2013.

SILVA, Érica C. Morais da. Conflito político-cultural na Antiguidade Tardia: o 'Levante das Estátuas' em Antioquia de Orontes (387 d.C.). 2012. Tese (Doutorado em História) - FHDSS/ Universidade Estadual Paulista, Franca, São Paulo, 2012.

SILVA, Gilvan Ventura da. Reis, Santos e Feiticeiros: Constâncio II e os fundamentos místicos da basiléia. (337-361). Vitória: Edufes, 2003. 
SPINELLI, Miguel. Helenização e Recriação de Sentidos. A Filosofia na Época da Expansão do Cristianismo - Séculos II, III e IV. Porto Alegre: EDIPUCRS, 2002.

TEJA, Ramon. Organizacion economica y social de Capadocia en el siglo IV, segun los Padres Capadocios. Universidad de Salamanca, 1974.

VAN NUFFELEN, Peter. Arius, Athanase et les autres: dimensions juridiques et politiques du retour d'exil ai IVe siècle. In: BLAUDEAU, Philippe (org.). Exil et Relégation les tribulations du Sage, et du Saint durant l'Antiquité Romaine et Chrétienne (ler-Vles. ap.J.-C.). Paris: De Boccard, 2008, p. 147-175.

WOODS, David. Valens: Valiant but flawed - Noel Lenski, Failure of Empire: Valens and the Roman State in The Fourth Century Ad. Journal of Roman Archaeology, 17, p. 729-734, 2004.

\section{Fontes}

BASILE de Cesarée. Contre Eunome. Introduction, traduction et notes de Bernard Sesboüé. Tome I, n²99; Tome II, n³05. Paris: Cerf, 1982-1983.

BASILE de Cesarée. Lettres. Texte établi et traduit par Yves Courtonne. Paris: Les Belles Lettres, 1957-1966, 3v.

CODE THEODOSIEN - LIVRE XVI. Les lois religieuses des empereurs romains de Constantin à Théodose II (312-438) - V. I. Texte latin: Theodor Mommsen - Traduction: Jean Rougé - Introduction et notes par Roland Delmaire (Université de Lille 3) avec la collaboration de François Richard (Université de Nancy 2) et d'une équipe du GDR 2135. Introdution, notes e index par Élisabeth Mangnou-Nortier. Paris: Les Éditions du Cerf, 2002.

EUNOME de Cyzique. Apologie. Introduction, Traduction et notes de Bernard Sesboüé. Tome II, n 305. Paris: Cerf, 1983.

GRÉGOIRE NAZIANZE, Saint. Lettres. Texte établi et traduit par Paul Gallay. Paris: Les Belles Lettres, 1964, 2v.

Grégoire de Nysse. Contre Eunome I. 1-146. Texte grec de W. Jaeger (GNO I,1) Introduction, traduction et notes par Raymond Winling. Paris: Les Éditions du Cerf, 2008.

Grégoire de Nysse. Contre Eunome I. 147-691. Texte grec de W. Jaeger (GNO I,1) Introduction, traduction et notes par Raymond Winling. Paris: Les Éditions du Cerf, 2010.

Grégoire de Nysse. Lettres. Introduction, texte critique, traduction, notes et index par Pierre Maraval. Paris: Les Éditions du Cerf, 1990.

Grégoire de Nysse. Vie de sainte Macrine. Introduction, texte critique, traduction, notes et index par Pierre Maraval. Paris: Les Éditions du Cerf, 1971.

GREGORII NYSENII OPERA. Epistulas Continens. Voluminis VIII. Fasciculus II. Ed. Georgius Pasquali. Florença: Berolini, 1925. 
GREGORY OF NYSSA. The Letters. Introduction, Translation and Commentary by Anna M. Silvas. Leiden, Boston: Brill, 2007.

MARCELLIN, Ammien. Histoire. Texte établi et traduit par Edouard Galletier avec la collaboration de Jacques Fontaine. Paris: Les Belles Lettres, 1978.

MARCELLINUS, Ammianus. History. Translated by John C. Rolfe. London: The Loeb Classical Library, 1982, 3v.

TEMISTIUS. Discursos Políticos. Con traducción al español de Joaquín Ponce Ritore. Madri: Gredos, 2000.

TEMISTIUS. The private Orations of Themistius. With an English translation by Robert J. Penella. California: University of California Press, 1999.

\section{Notas}

1 Os cristãos homeus defendiam que o Filho (segunda pessoa do dogma trinitário) é semelhante (ouoıs - homoios) ao Pai (primeira pessoa do dogma trinitário), ou seja, a substância do Filho é semelhante à do Pai. Obtiveram vitória significativa durante o Concílio de Constantinopla de 360 d.C. Também são retratados na literatura patrística e na historiografia por Homeos, Homoianos ou simplesmente arianos. Para discussão aprofundada ver: PAPA, (2013).

2 Poderíamos selecionar também medidas administrativas com vários propósitos, dentre os quais o fiscal e o religioso também estavam presentes, mas por uma questão de método, seleção e espaço, não serão abordadas neste artigo.

3 Para considerações e diferenças entre exilium, relegatio e deportatio ver: DELMAIRE, (2008, p. 116-122).

${ }^{4}$ Há um debate historiográfico acerca da data de morte de Basílio de Cesareia que discute a possibilidade da morte ter ocorrido em 377 , data da promulgação de seu exílio por Valente; no final de 378 e, ainda, a tradicional data no início de 379 d.C. Sobre essa discussão historiográfica ver: PAPA, (2013, p. 121).

Helena Amália PAPA é professora do Departamento de História e do Programa de Pós-graduação em História do Centro de Ciências Humanas da Unimontes - Universidade Estadual de Montes Claros. Pesquisa sobre a história dos cristianismos na Antiguidade Tardia. Dentre suas publicações destacam-se: A Contenda entre Basilio de Cesareia e Eunômio e Cízico (Séc. IV d.C.). Uma análise político-religiosa (São Paulo: Annablume/FAPESP, 2013) e a coorganização da coletânea Imagens e Textos: Interpretações sobre Cultura e Poder na Antiguidade (São Paulo: Alameda/ FAPESP, 2020).

\section{Editores}

Submissão: 31/05/2020 